\title{
RESEÑA CRÍTICA SOBRE EL CONCEPTO DE TERCER ESPACIO DE HOMI BHABHA: DEL LOCAL DE LA CULTURA HASTA NUEVAS MINORÍAS, NUEVOS DERECHOS - NOTAS SOBRE COSMOPOLITISMO VERNÁCULOS
}

Catalina Revollo Pardo ${ }^{\mathrm{i}}$

\begin{abstract}
Resumen: Con la intención de aportar elementos para el área de la educación, esta reseña crítica tiene como objetivo describir la trayectoria del concepto de tercer espacio del profesor indiano Homi Bhabha, por medio de la descripción del concepto en su momento inicial en El Local de la Cultura, y su reelaboración expuesta en su reciente obra Nuevas Minorías, Nuevos Derechos: notas sobre cosmopolitismo vernáculos. El análisis apunta elementos de su biografía académica y laboral, como puntos centrales para comprender el giro que tomo la comprensión actual del concepto de tercer espacio, relacionada a la construcción de los derechos de las minorías.
\end{abstract}

Palabras clave: Homi Bhabha; Crítica Poscolonial; Derechos de las minorías.

\section{RESENHA CRÍTICA SOBRE O CONCEITO DE TERCEIRO ESPAÇO DE HOMI BHABHA: DO LOCAL DA CULTURA ATÉ NOVAS MINORIAS, NOVOS DIREITOS - NOTAS SOBRE COSMOPOLITISMO VERNÁCULO}

Resumo: Com a intenção de trazer elementos para a área da educação, esta resenha crítica tem como objetivo descrever a trajetória do conceito do terceiro espaço do professor indiano Homi Bhabha, por meio da descrição do conceito no seu momento inicial no Local da Cultura, e sua releitura exposta em sua atual obra Nuevas Minorías, Nuevos Derechos: notas sobre cosmopolitismo vernáculos. A análise revela elementos de sua biografia académica e laboral, como pontos centrais para compreender a as novas ideias que complementaram a compreensão atual do conceito do terceiro espaço, relacionada à construção dos direitos das minorias.

Palavras chave: Homi Bhabha; Crítica Pós-colonial; Direitos das minorias.

Homi Bhabha nació en Bombay en 1949, inicia sus estudios en literatura inglesa en la India y se traslada a Oxford, para continuar con su estudios. En la actualidad es profesor de Inglés y Estudios Afroamericanos, director del Mahindara Humanites Center en Harvard, asesor de: la Unesco en diversidad cultural, World Economic Forum de Davos sobre derechos humanos entre otros renombrados cargos, y autor de relevantes ensayos, lo posiciona como uno de los principales representantes de la crítica poscolonial.

Los estudios poscoloniales son una serie de referencias epistemológicas criticas a la modernidad, las cuales no son una única matriz teórica y a su vez están presentes en distintas 
áreas del conocimiento. Esta crítica se inician con las reflexión de autores desplazados, miembros de la diáspora negra o migrantes de países denominados del "tercer mundo"; colonias o ex colonias, radicados en universidades europeas, del Reino Unido y Estados Unidos. La construcción y difusión inicial de esta perspectiva, se da en los estudios literarios en los Estados Unidos e Inglaterra, estos autores se interesaron por el análisis, la preservación y documentación de la literatura producida por autores marginales de las colonias o ex colonias (considerados por la crítica literaria tradicional, como incultos, salvajes o primitivos).

Según Siskind (2013, p. 14) la teoría poscolonial se estructura por medio del cuestionamiento crítico a los modelos culturales europeos (y en secuencia, los estadounidenses), preguntándose: ¿Como representaron la diferencias de sus otros coloniales, destacando las instancias textuales en que los sujetos minoritarios lograron socavar y subvertir los dispositivos discursivos que sustenta la hegemonía colonial? La respuesta, según el autor, se da por una doble maniobra de desarticulación contra-hegemónica y de reconocimiento de la agencia subalterna.

Para Costa (2006, p. 120), las alternativas epistemológicas de la poscolonialidad, que pueden resolver el cuestionamiento están clasificadas en tres propuestas metodológicas: (a) el análisis de historias entrelazadas, reinterpretando la historia moderna, para destacar la ceguera epistemológica de la división moderna del mundo y el papel de las colonias como campo de experimentación de la modernidad; (b) el análisis del lugar de enunciación poscolonial, el cual busca un lugar de enunciación escapando de esencialismos, transgrediendo las fronteras culturales del pensamiento colonial; (c) el análisis de la diferencia del sujeto, basado en el concepto de différance de Derrida, que sucede en la trama de las representaciones. Para localizar a Bhabha en estas alternativas epistemológicas clasificadas por Costa, debemos destacar que desde los años ochentas el profesor indiano, proponía sus primeros análisis críticos y dislocados sobre el lugar de la enunciación del sujeto poscolonial.

El profesor de literatura latinoamericana, Mariano Siskind (2013, p. 13), destaca lo dicho por el profesor W.J.T Mitchell, editor de la revista Critical Inquiry, al recibir en 1984 la sumisión del ensayo Signs taken for Wonders: Questions of Ambivalence and Authority under a tree outside Delhi, May 1817 (1985) de Bhabha: el joven profesor habla desde los márgenes provinciales y coloniales de la cultura inglesa. Este ensayo se convertiría diez años mas tarde en uno de los temas centrales de El Lugar de la Cultura, su principal obra publicada en 1994, 
clave para la crítica poscolonial, que ya venia diseñado con sus obras anteriores: Difference, Discrimination and the Discurse of Colonialism (1983) y Nación y Narración (1990).

Se considera que la crítica de Bhabha esta dentro de un segundo momento fundacional de los estudios poscoloniales y complementa los textos inaugurales como El Orientalismo (SAID, 1978), The Empire Writes Back (ASHCROT; GRIFFITHS; TIFFIN, 1989), entre otros. En el caso del Orientalismo, Said, describe la construcción europea de la otredad por medio del esencialismo, inventado al oriente como espacio de otredad absoluta ${ }^{\text {ii }}$. En cambio Bhabha propone pensar la dominación en términos de una hegemonía no absoluta marcada por la construcción ambivalente de una autoridad colonial fundada en el acto de violencia, pero que busca a la vez instituir civilización, se preocupa por señalar los espacios de resistencia constituidos en los límites internos y externos de la nación. (SISKIND, 2013, p. 15)

Para comprender mejor la articulación de la propuesta de Bhabha, es menester localizar en su trayectoria, en que momento y como se comienza a interesar por la enunciación del sujeto poscolonial, en la entrevista hecha en 2012, en Cambridge por Siskind a Bhabha, se explica como en el proceso de su investigación de doctorado, trabajando sobre la obra de V.S. Naipaul ${ }^{\text {iii }}$, reverberaba un eco genuino en el lenguaje de la obra, con un tipo particular de subjetividad (BHABHA, 2013, p. 196), Bhabha resalta que fue justamente en el plano del lenguaje, no tanto en los antecedentes, la historia, la trama, la puesta en escena o las ideas detrás del relato (2013, p. 196) que despertó su interés.

Su uso particular del inglés transmitía una sensación de temor y ansiedad que me recordó parte de mi propia experiencia, algo que no encontraba en los novelistas indios partidarios del realismo social... Estos escritores escribían en el mejor idioma que conocían, un lenguaje verdaderamente occidental (aunque utilizando formulaciones que para ellos tenían un timbre indio...). Si bien eran significativas y mucho mas cercanas a mí en términos de experiencia, esas novelas no me hacían recordar mi pasado del mismo modo en que las novelas de Naipaul me recordaban algo que no podría haber articulado nunca en ese momento: cierta mezcla de pasión e incomodidad a respecto del idioma que había heredado.

Ahí había algo que me resultaba tremendamente importante e íntimo. Era un inglés imperfecto, un dialecto en cierto sentido, perfectamente formado, pero angustiado por su propia existencia. ${ }^{\text {iv }}$ (BHABHA, 2013, p. 196)

En su narrativa se puede materializar de manera más didáctica, de donde parte su interés por estudiar las estructuras del discurso colonial, lo que nos permitirá adentrarnos con más sencillez en la complejidad que caracteriza al autor. Las múltiples y diversas influencias 
epistemológicas con las cuales ha construido el autor su obra, se derivan de la insatisfacción que encontraba en las propuestas teórico-metodológica tradicionales que circulaban hasta el momento en las esferas de los estudios literarios. Es por medio de una ingeniosa interpretación del psicoanálisis lacaniano, la filosofía posestructuralista, los autores de la diáspora negra (entre otros), que Bhabha consigue desarrollar sus principales aportes a los estudios poscoloniales.

\section{El Tercer Espacio}

La temporalidad no sincrónica de las culturas nacionales y globales abre un espacio cultural - un tercer espacio- donde la negociación de las diferencias inconmensurables crea una tensión peculiar a las existencias fronterizas.

(BHABHA, 1998, p. 300)

Según Costa (2006, p. 123), a Bhabha le interesa que los espacios de enunciación no sean definidos en polaridades, sino que estén situados entre las divisiones, bien en la grieta de las fronteras que define cualquier identidad colectiva. El lugar de enunciación entre los sistemas de representación, Bhabha lo define como el tercero espacio, el cual no es un locus fijo en la tesitura social, donde se identifica un juego lingüístico en el que las diferencias culturales son construidas y negociadas, advirtiendo que la acción creativa es la que subvierte y redefine el signo, a partir de un lugar de enunciación dislocado de los sistemas de representación cerrados de la modernidad, es un lugar de frontera, cargado de fragmentaciones y ambivalencias.

La diferencia lingüística que es base de cualquier performance cultural es dramatizada en el relato semiótico común de la disyunción entre el sujeto de una proposición (enoncé) y el sujeto de la enunciación, que no es representado en el enunciado, pero que es el reconocimiento de su incrustación e interpelación discursiva, su posición cultural, su referencia a un tiempo presente y a un espacio específico. El pacto de la interpretación nunca es simplemente un acto de comunicación entre el Yo y el Usted designados en el enunciado. La producción de sentido requiere que esos dos lugares sean movilizados al pasar por un tercer espacio, que representa tanto las condiciones generales del lenguaje y la implicación específica del enunciado en una estrategia performática e institucional la cual no puede, en si, tener consciencia, lo que esa relación inconsciente introduce es una ambivalencia en el acto de la interpretación. (BHABHA, 1998, p. 66) 
Según Siskind (2013, p. 13), en El Local de la Cultura ${ }^{v}$, el autor esta interesado en lugares liminales ubicados en los clivajes de la nación, que el va denominar como entre-lugares de donde resultan procesos de hibridación cultural, que desplazan, resignifican y desfiguran las historias y tradiciones estables que los preceden para establecer nuevas formas de autoridad, ilegibles desde las epistemologías que han sido dislocadas (como el imperialismo británico o el nacionalismo poscolonial indio), generando nuevas identidades que demandan nuevos discursos de significación.

El entre-lugar que nos explica Bhabha (1998) es un terreno para la elaboración de estrategias de subjetivación, que dan inicio a nuevos signos de identidad, innovación y contestación. Es el entre-lugar que carga el peso del significado de la cultura, siendo la característica del tercer espacio. La intervención del tercer espacio de la enunciación, hace que la estructura referencial se vuelva un proceso ambivalente, destruyendo el espejo de la representación, así la temporalidad disruptiva de la enunciación desplaza a la narrativa de la nación occidental. Es en este espacio contradictorio y ambivalente de la enunciación que se garantiza que el significado y símbolos de la cultura no sean fijo o universales, ya que los símbolos pueden ser traducidos. Es en este tercer espacio en el que resultan las identidades hibridas.

El Hibridismo en Bhabha, es el retorno del contenido y la forma de la autoridad colonial, ya que lo que se niega, no se reprime, ya que aflora repetido en lo hibrido, la cual es una fuerza doble y parcial, la cual no es la introducción del relativismo cultural, ni una posición de síntesis que resuelve la dialéctica de las culturas.

Si hibridismo es la herejía, blasfemar es soñar. Soñar no con el pasado o presente y ni con el presente continuo; no es el sueño nostálgico de la tradición, ni el sueño utópico del progreso moderno, es el sueño de la traducción, como sur-vivre, como "sobrevivencia", como Derrida traduce el "tiempo" del concepto benjaminiano de la sobrevida de la traducción, el acto de vivir en las fronteras. Rushdie (versos satánicos) traduce esto como el sueño de sobrevivencia del migrante: un intersticio de iniciación; una condición del hibridismo que da poder; un surgimiento que transforma el "retorno" en reinscripción o redescripción, una interacción que no es tardía, pero irónica e insurgente. Esto porque la sobrevivencia del migrante depende, como afirma Rushdie, de la descubierta de "como lo nuevo entra en el mundo". La cuestión central es la elaboración de relaciones a través de los elementos inestables de la literatura y de la vida - el peligroso encuentro marcado con lo "intraducible" - en vez de se acomodar en nombres prefabricados. (BHABHA, 1998, p. 311) 
Según Costa (2006, p. 123), el concepto de hibridismo toma dos caminos: uno de carácter deconstructivo, que corresponde al trazo hibrido de toda construcción social, haciendo heterogéneo el lugar de enunciación, y otro de carácter normativo de la condición global cosmopolita, la cual no esta basada en el exotismo del multiculturalismo o en la diversidad cultural y si en la articulación e inscripción e culturas hibridas.

El concepto de hibridismo ha generado varias criticas, por las interpretaciones que ha recibido como una lectura que tiende a caer en el error del cual es crítico, universalizar la cultura. al mismo tiempo aparentar una concepción universal de los procesos culturales. Lo que complemento con Siskind (2013, p. 12), cuando afirma que la sobre exposición que tuvieron sus ideas de Bhabha, en consecuencia de su eficacia, terminaron por crear la imagen errónea de un pensamiento estático y reducible a las determinaciones poscoloniales y anglófonas de su contexto histórico inmediato.

En palabras de Bhabha (1998)

Para aprender la ambivalencia del hibridismo, el debe ser distinguido de una inversión que sugeriría que lo original es, de hecho, apenas un "efecto". El hibridismo no tiene para brindar una perspectiva de profundidad o de verdad: no es un tercer termino que resuelve la tensión entre dos culturas, o las dos caras del libro, en un juego dialéctico de "reconocimiento". El desplazamiento del símbolo, a signo, crea una crisis para cualquier concepto de autoridad basado en un sistema de reconocimiento: es la especulación colonial, doblemente inscrita, no produce un espejo donde el yo aprende de si mismo; ella esta siempre dividida entre el yo y su duplicación, lo hibrido. (p. 165)

De acuerdo con la introducción de Siskind desde la publicación de El Lugar de la Cultura, el escribió ensayos, dicto conferencias, dio clases y concedió entrevistas que establecieron continuidades, rupturas y resignificaciones a respecto de los materiales estéticos y críticos que había utilizado para elaborar su análisis del discurso colonial y los procesos de identificación intersticiales (2013, p. 13). Sus nuevas ideas sobre el tercer espacio están relacionadas con el contexto de las demandas de ética, ancladas en un universalismo localizado al que denomina "cosmopolitismo vernáculo", se trata del lugar de la enunciación de un compromiso con los derechos del otro, un entre lugar donde se articula una decisión éticopolítica, sobre la necesidad de articular nuevos derechos (2013, p. 14). 


\section{Cosmopolitismos Vernáculos}

En la propuesta por relocalizar la cultura, Bhabha hace una relectura del Local de la Cultura, en la que según Siskind (2013, p. 19) desplaza la centralidad de la imaginación poscolonial para pensar sobre los cosmopolitismos "marginales", que Bhabha va a denominar mas acertadamente como vernáculos, en la que las minorías liminales se oponen a un cosmopolitismo global, el cual esta basado en la globalización de relaciones nacionales y no es capaz de lidiar con la exclusión de las minorías. En su libro Nuevas Minorías, Nuevos Derechos: notas sobre cosmopolitismo vernáculos (BHABHA, 2013), plantea que,

Sostener en común un concepto como tercer espacio es comenzar a entender que pensar y escribir son actos de traducción. Para mi el tercer espacio es imprescindible fuera de la localidad de la traducción cultural. El conocimiento local fue la primera pista que me llevo a pensar en el tercer espacio, a causa de cierto errores de traducción en el contexto de algunos discursos evangélicos de comienzos del siglo XIX dedicados a la conversión de los hindúes en el norte de la India (p. 80).

Ya para la entrada del siglo XXI, Bhabha va a reflexionar sobre los estados de violencias de finales e inicios del siglo, lo que hace comprender que el tercer espacio esta comprometido con los procesos de transición política y trasformación ética de las sociedades azotadas por la violencia. Nos da el ejemplo de cómo las Comisiones de la Verdad ofrecen un tercer espacio dialógico,

Es un tiempo y un lugar que existen en medio del violento y la víctima, del acusado y al acusador, de la acusación y la confesión. Y ese lugar intermedio se convierte en el terreno de discusión, disputa, confesión, disculpas y negociación donde juntos enfrentan las asimetrías del trauma social, no como un "mismo pueblo", sino como gente de una misma causa. (BHABHA, 2013, p. 81)

El mismo Bhabha explica que la trasmisión de estas "culturas de supervivencia" no tiene lugar en el ordenado museo de las culturas nacionales, estas culturas están vinculadas en el orden de las experiencias afectivas las cuales tiene la capacidad de transformar las estrategias críticas de las ciencias humanas y sociales.

El giro que le dio Bhabha a su pensamiento en las ultimas décadas, se puede caracterizar por un posicionamiento franco en el lugar discursivo de la militancia por una nueva concepción de las humanidades, como espacio virtual en el que se cruzan una pluralidad de discursos 
sociales y demandas dispares e inconmensurables. Esta interesado en hacer una relación entre las humanidades y los derechos humanos, proponiendo lo que Bhabha va a denominar como humanistas sensibles (SISKIND, 2013, p. 20).

Una lengua que tiene la capacidad de articular la condición humana como una relación afectiva con la opresión, la humillación, la violencia, la pobreza, la ignorancia, la desnutrición, pero que al mismo tiempo tiene el poder de darle forma a lo humano como aspiración a la libertad, la salud, la representación política, la diferencia y la erradicación del hambre. Los humanistas como los militantes por los derechos humanos, trabajan o deben trabajar, para la realización de ese espacio de enunciación e interpretación. (BHABHA, 2013, p. 20)

La obra de Bhabha es bastante conocida por sus ideas que evaden los binarismos para comprender el conflicto cultural. El da el ejemplo de cómo el discurso público tiende a representar el lugar de los trabajadores inmigrantes e indocumentados, en términos de marginalidad, pero ellos realmente, están localizados en un lugar social intersticial. Es un tercer espacio en medio del cosmopolitismo global. Son los cosmopolitismos vernáculos que están en los intersticios de una economía y sistema políticos que no podría funcionar sin estos, lo que implica la responsabilidad de configurar derechos capaces de dar cuenta de estos modos intersticiales y traducibles de agencia que son inconmensurables con un sujeto de derechos concebidos en términos universales, autónomos y soberanos. Los cosmopolitismos vernáculos cuestionan como los derechos se deben plantear no desde el Estado, sino desde un lugar de enunciación minoritario, ya que el Estado no es capaz de absorber por completo.

Para concluir esta pertinente relocalización de la evolución del concepto tercer espacio de Bhabha, por medio del modesto análisis de sus enclaves: hibridismo y la renovada concepción de cosmopolitismos vernáculos, relacionados con su trayectoria académica y laboral; brinda elementos y recursos para analizar y entrever las interfaces culturales en el actual contexto social. Para el área de la educación, este legado sin duda diseña posibles caminos, desde una perspectiva poscolonial renovada para el siglo XXI, con la construcción de una practica educativa (otra) consiente y comprometida con los derechos de las minorías, que se enuncian y materializan desde terceros espacios, para generar proceso educativos de reconocimiento propios y conflictivamente híbridos desde la lógica de la interculturalidad. 


\section{Referencias}

BHABHA, Homi. El Lugar de la Cultura. Buenos Aires. Manantial. 1998

. Nuevas Minorías Nuevos Derechos, Notas sobre Cosmopolitismo Vernáculo. Buenos Aires: Siglo Veintiuno editores. 2013

COSTA, Sergio. Desprovincializando a sociologia: a contribuição pós-colonial. Revista Brasileira de Ciências Sociais. v. 21, n. 60. 2006.

SISKIND, Mariano. Los Intersticios de lo nuevo: para una ética de las dislocaciones globales. In: BHABHA, Homi. (org). Nuevas Minorías Nuevos Derechos, Notas sobre Cosmopolitismo Vernáculo. Buenos Aires: Siglo Veintiuno editores, 2013.

\footnotetext{
${ }^{\text {i }}$ Pós-doutoranda e professora colaboradora do Programa de Psicossociologia de Comunidades e Ecologia Social (EICOS/UFRJ).

ii Propuesta epistemología poscolonial, que de acuerdo a la clasificación de Costa (2006), puede estar inserida en el análisis de historias entrelazadas.

iii Sir Vidiadhar Surajprasad Naipaul, escritor de Trinidad y Tobago, con familia de descendientes indianos.

${ }^{\text {iv }}$ Aun haciendo referencia al inglés de Naipaul.

v Publicado en 1994, traducido al portugués y publicado en el Brasil en 1998 por la editora UFMG en Belo Horizonte y traducido al español y publicado en argentina en 2002 por la Editora Manantial en Buenos Aires, (considerada una traducción no tan primorosa como la brasileña). Es un texto que en el Brasil ha sido muy bien utilizado en los análisis de la literatura comparada y en los varios discursos otros discursos disciplinarios, como en la antropología, sociología, psicosociología de comunidades, educación, entre otros.
} 